\title{
SUSTENTABILIDADE DE SISTEMAS ORGÂNICOS COM PLANTAS DE COBERTURA NA CULTURA DO ARROZ, POR MEIO DE ALTERAÇÕES FÍSICAS DO SOLO ${ }^{1}$
}

\author{
Renata Alves de Aguiar², José Aloísio Alves Moreira ${ }^{3}$, \\ Luís Fernando Stone ${ }^{3}$, Tatiely Gomes Bernardes ${ }^{2}$, Roberta Paula de Jesus ${ }^{2}$
}

\section{ABSTRACT \\ ORGANIC SYSTEMS SUSTAINABILITY USING COVER CROPS IN RICE CULTIVATION THROUGH SOIL PHYSICAL ATTRIBUTES CHANGES}

To evaluate the influence of cover crops on Oxisol physical attributes, in an organic production system with conventional tillage, a study was conducted at Embrapa Arroz e Feijão, Santo Antônio de Goiás, Goiás State, Brazil, for two years, in a succession cover crops-rice, in which cover crops were sown in the autumn/winter and the subsequent crop, rice cultivar Aimoré, was sown in the summer. Five cover crops were used: Velvet bean (Mucuna aterrima), Sunn hemp (Crotalaria juncea), Pigeon pea (Cajanus cajan), Broom sorghum (Sorghum technicum), and spontaneous vegetation fallowing. A randomized blocks design with four replications was used. In the second year of experimentation (2005), soil samples were collected from plots and from a close forest, at depths of $0.00-0.10 \mathrm{~m}, 0.10-0.20 \mathrm{~m}$, and $0.20-0.30 \mathrm{~m}$, to determine organic matter content (SOC), soil physical properties, S index, and soil aggregation. The cover crops management was carried out at the flowering stage and its biomass incorporated into soil profile. For total porosity, microporosity and bulk density, there were no significant differences among depths, for different cover crops. For $\mathrm{S}$ index, for all treatments at the 0.00-0.10 m layer depth, values between 0.020 and 0.035 , characterizing intermediate soil physical quality, were found. The percentage of aggregates with a diameter larger than $2 \mathrm{~mm}$ and the weighted average diameter of aggregates were higher at the $0.10-0.20 \mathrm{~m}$ layer depth. SOC decreased with depth, independently of cover crops.

KEY-WORDS: Cover crops; soil tillage; porosity; aggregate stability.

\section{INTRODUÇÃO}

Para produção, sem degradação dos recursos naturais solo e água, é necessário manter a estru-

\section{RESUMO}

O presente trabalho teve como objetivo avaliar o efeito de diferentes plantas de cobertura de solo sobre os atributos físicos de um Latossolo Vermelho distrófico, em sistema de produção orgânico, com preparo convencional. O trabalho foi conduzido, por dois anos, na área experimental da Embrapa Arroz e Feijão, em Santo Antônio de Goiás, GO, em um sistema de sucessão de plantas de cobertura-arroz, no qual as plantas de cobertura eram semeadas no outono/inverno e a cultura subsequente, o arroz, cultivar Aimoré, semeada no verão. Foram utilizadas as seguintes plantas de cobertura: mucuna preta (Mucuna aterrima), crotalária (Crotalaria juncea), guandu-anão (Cajanus cajan), sorgo vassoura (Sorghum technicum) e pousio com vegetação espontânea. O delineamento experimental foi de blocos ao acaso, com quatro repetições. Foram coletadas, no segundo ano de experimentação (2005), amostras de solo, nas parcelas e em mata próxima, nas profundidades de $0,00-0,10 \mathrm{~m} ; 0,10-0,20 \mathrm{~m}$; e 0,20-0,30 m, para determinação do teor de matéria orgânica (MO), atributos físicos, índice $\mathrm{S}$ e estado de agregação do solo. O manejo das plantas de cobertura de solo foi efetuado por ocasião do florescimento. A biomassa foi incorporada ao perfil por meio de aração. Para a porosidade total, microporosidade e densidade do solo, não foram observadas diferenças significativas entre as profundidades, para as diferentes plantas de cobertura do solo. Para o índice S, observou-se, para todos os tratamentos, na camada $0-10 \mathrm{~m}$ de profundidade, valores entre 0,020 e 0,035 , que caracterizam solos com qualidade física intermediária. A porcentagem de agregados com diâmetro maior que $2 \mathrm{~mm}$ e o diâmetro médio ponderado dos agregados foram maiores, independentemente de cobertura de solo, na camada 0,10-0,20 $\mathrm{m}$ de profundidade. Também, independentemente da cobertura de solo, o conteúdo de matéria orgânica decresceu com a profundidade do solo.

PALAVRAS-CHAVE: Plantas de cobertura; preparo do solo; porosidade; estabilidade de agregados.

tura física, o teor de matéria orgânica, o nível dos nutrientes e a atividade biológica do solo. O plantio direto tem sido uma das práticas conservacionistas utilizadas como alternativa aos sistemas conven-

1. Trabalho recebido em set./2008 e aceito para publicação em jun./2010 (nº registro: PAT 4843/ DOI: 10.5216/pat.v40i2.4843).

2. Universidade Federal de Goiás, Escola de Agronomia e Engenharia de Alimentos, Setor de Fitossanidade, Goiânia, GO, Brasil. E-mails: renatalvesufg@yahoo.com.br, tatielygb@bol.com.br, rpauladejesus@yahoo.com.br.

3. Embrapa Arroz e Feijão, Departamento de Irrigação e Drenagem, Santo Antônio de Goiás, GO, Brasil.

E-mails: jaloisio@cnpms.embrapa.br, stone@cnpaf.embrapa.br. 
cionais de manejo do solo em uso na agricultura intensiva (Freitas 1994). Entretanto, nos sistemas de produção orgânicos, como não se utilizam herbicidas, tem sido adotado, como forma de controle mecânico de plantas espontâneas, o sistema de preparo convencional do solo (SPC). Neste sistema, o preparo do solo é realizado com arados de aiveca e discos, incluindo as grades aradoras. A preferência por estes equipamentos deve-se à sua facilidade de operação, em condições adversas dos solos. Para operações com arados de aiveca e discos, há um maior gasto de combustível. Já para trabalhos com as grades aradoras, este consumo é menor, em função, principalmente, da sua alta capacidade de trabalho. Para o cultivo do arroz de terras altas, o sistema convencional empregando grades aradoras é mais utilizado, devido à dificuldade de adaptação desta cultura ao sistema plantio direto.

Sabe-se que, em geral, os sistemas convencionais de manejo do solo em uso na agricultura intensiva promovem a diminuição da dinâmica da matéria orgânica e da atividade biológica, afetando a naturalmente frágil condição estrutural dos solos tropicais e modificando seu comportamento e processos aí presentes (Freitas 1994). Assim, a rotação apropriada de culturas, a manutenção dos níveis adequados de nutrientes e as práticas de conservação são algumas estratégias importantes no manejo adequado dos solos.

Os solos, na região dos Cerrados, apresentam alta taxa de decomposição do material orgânico, sendo necessário o contínuo aporte do mesmo para manter sua estrutura em condições favoráveis ao desenvolvimento das culturas. Além disso, os sistemas agrícolas presentes, em geral, têm baixa produção de fitomassa. Assim, é de fundamental importância avaliar sistemas agrícolas, dentre eles os orgânicos, com culturas de rotação e de cobertura vegetal, incluindo as plantas de cobertura, objetivando a melhoria da qualidade física do solo, da produtividade e da sustentabilidade ambiental (Beutler et al. 2003).

Vários parâmetros relacionados ao solo podem ser utilizados como indicadores da sustentabilidade de um sistema de produção. Dentre eles, está a estrutura do solo, por meio de seu estado de agregação e pela estabilidade de seus agregados, e, de utilização mais recente, o índice $\mathrm{S}$.

A estrutura exerce grande influência nos ciclos de nutrientes, na capacidade de receber, armazenar e transmitir água, na difusão de gases, penetração das raízes e capacidade de resistir à erosão, que são fatores importantes para o crescimento das plantas (Portugal et al. 2008). Assim, a estrutura do solo, geralmente avaliada pela distribuição e estabilidade dos agregados, tem sido proposta como um importante indicador da sua qualidade (Salton et al. 2008).

Dentre os vários agentes importantes de formação de agregados, estão as gramíneas, que, geralmente, devido ao sistema radicular abundante, contribuem para agregação do solo (Carpenedo \& Mielniczuk 1990). Também, podem ser utilizadas as leguminosas, que, além de fornecer nitrogênio, colaboram para a distribuição dos agregados com maior percentual na classe $>2,00 \mathrm{~mm}$ (Perin et al. 2000).

A qualidade física se manifesta de várias maneiras. São exemplos de pobre qualidade física do solo a baixa infiltração de água, escorrimento de água sobre a superfície do solo, má aeração, pobre desenvolvimento das raízes e pobre trabalhabilidade do solo. Já a boa qualidade física do solo ocorre quando o mesmo exibe características opostas ou ausentes das condições listadas acima. É comum os solos exibirem estes problemas físicos simultaneamente. A razão de todos estes sintomas tem uma causa comum: a pobre estrutura do solo. Em função disto, Dexter (2004) propôs um índice de qualidade física do solo, o índice $\mathrm{S}$, de fácil mensuração e que torna possível a comparação direta dos efeitos de diferentes práticas de manejo e condições físicas. Ele é igual à declividade da curva de retenção da água do solo, no seu ponto de inflexão. A maioria da declividade $\mathrm{S}$, da curva de retenção da água do solo, no ponto de inflexão, é devida, principalmente, à porosidade microestrutural $\mathrm{e}$, portanto, $\mathrm{S}$ governa, diretamente, muitos dos principais atributos físicos do solo. Assim, a presença de poros estruturais e um alto valor de $\mathrm{S}$ são essenciais para uma boa qualidade do solo. Segundo Dexter (2004), o limite entre solos com boa e pobre qualidade estrutural ocorre no valor aproximado de $\mathrm{S}=0,035$. Valores de $\mathrm{S}<0,020$ estão, claramente, associados a condições físicas de solos muito pobres.

O objetivo deste trabalho foi verificar a influência de diferentes plantas em atributos físicos do solo, no estado de agregação e no índice $\mathrm{S}$ de um Latossolo Vermelho distrófico de Cerrado, cultivado com arroz de terras altas, no sistema de preparo convencional, em sistema de produção orgânico. 


\section{MATERIAL E MÉTODOS}

O experimento foi realizado na Embrapa Arroz e Feijão, no município de Santo Antônio de Goiás (GO), em Latossolo Vermelho distrófico, textura argilosa, com $570 \mathrm{~g} \mathrm{~kg}^{-1}$ de areia, $130 \mathrm{~g} \mathrm{~kg}^{-1}$ de silte e $300 \mathrm{~g} \mathrm{~kg}^{-1}$ de argila. O delineamento experimental foi de blocos casualizados, com cinco tratamentos e quatro repetições e a análise estatística realizada com auxílio do programa estatístico SAS, sendo as médias dos tratamentos comparadas pelo teste Tukey, a 5\% de significância. Os tratamentos foram: Mucuna preta (Mucuna aterrima Merr.), Crotalária juncea (Crotalaria juncea L.), Guandu-anão (Cajanus cajan), Sorgo vassoura (Sorghum technicum) e Pousio (vegetação espontânea). O experimento foi conduzido por dois anos, em sistema de produção orgânico, baseado na substituição total de insumos industriais, com preparo convencional, em um sistema de sucessão plantas de cobertura-arroz.

A semeadura das plantas de cobertura do solo foi feita no período subsequente ao término das chuvas (junho) e a semeadura do arroz efetuada no início das chuvas (novembro). O arroz, cultivar Aimoré, foi semeado em espaçamento de $0,35 \mathrm{~m}$ entre fileiras, com oitenta sementes por metro, e as espécies de cobertura no espaçamento de $0,45 \mathrm{~m}$ entre linhas.

Para as leguminosas, utilizou-se inoculante específico: Bradyrhizobium spp. 6156, 6157, para guandu anão; Bradyrhizobium sp. 6158, para mucuna-preta; e Bradyrhizobium spp. 6145, 6156, para crotalária. Na floração, foram efetuadas coletas para determinação do acúmulo de biomassa seca, pelo método do ponto quadrado, quando se retiram amostras de plantas em $0,50 \mathrm{~m}$ de comprimento, em duas fileiras de plantas, em um único ponto (Sppeding \& Large 1957). As plantas amostradas foram colocadas em estufa de ventilação forçada, a $65^{\circ} \mathrm{C}$, até peso constante, para obtenção da biomassa seca. Logo após, foram pesadas e moídas em moinho Willey, equipado com peneira de 40 mesh, para a determinação do teor de nitrogênio total, pelo método semimicro Kjeldhall.

As plantas de cobertura do solo características de cada tratamento, excetuando-se a testemunha, foram cortadas com cutelo e deixadas na superfície do solo. O manejo foi concluído cerca de sessenta dias depois, quando a palhada foi incorporada ao solo, com grade aradora $(25 \mathrm{~cm})$ e arado de aiveca $(40 \mathrm{~cm})$. Em épocas anteriores, de acordo com o histórico da área, a recuperação da fertilidade do solo foi feita com a adição de fosfato natural $\left(810 \mathrm{~kg} \mathrm{ha}^{-1}\right)$, sulfato de potássio $\left(60 \mathrm{~kg} \mathrm{ha}^{-1}\right)$ e calagem $\left(2.000 \mathrm{~kg} \mathrm{ha}^{-1}\right)$.

As avaliações físicas, hídricas e químicas foram realizadas no segundo ano de experimentação. Para as avaliações físicas, foram retiradas amostras de solo, nas camadas $0,00-0,10 \mathrm{~m} ; 0,10-0,20 \mathrm{~m}$; e 0,20 $0,30 \mathrm{~m}$ de profundidade, com estrutura deformada, para a estabilidade de agregados (Embrapa 1997), e indeformada, para densidade do solo (Ds), relações de porosidade, porosidade total (PT), microporosidade (Mic), macroporosidade (Mac) e retenção de água (Embrapa 1997).

Para a determinação da estabilidade de agregados, os torrões foram tamisados, em peneiras de $2 \mathrm{~mm}$, para a análise via úmida. Depois de preparadas, as amostras foram transferidas para o aparelho de Yoder, com peneiras de malhas de 2,0 mm; $1,0 \mathrm{~mm} ; 0,5 \mathrm{~mm} ; 0,25 \mathrm{~mm}$; e 0,105 mm de abertura (Embrapa 1997). Foram calculados o diâmetro médio ponderado (DMP) e a porcentagem de agregados estáveis $>2,00 \mathrm{~mm}$.

A porosidade total foi determinada pela relação 1 - Ds/Dp, em que Dp é a densidade de partículas. Foi considerado como valor de microporosidade a quantidade de água retida pelo solo, à tensão de $6 \mathrm{kPa}$. A macroporosidade foi obtida pela diferença entre a porosidade total e a microporosidade. A retenção de água, nas tensões $0 \mathrm{kPa}, 6 \mathrm{kPa}, 8 \mathrm{kPa}, 10 \mathrm{kPa}$, $33 \mathrm{kPa}, 60 \mathrm{kPa}, 100 \mathrm{kPa}$ e $1.500 \mathrm{kPa}$, foi determinada por meio de uma centrífuga, para obtenção da curva de retenção de água do solo. As curvas de retenção foram ajustadas utilizando-se o modelo proposto por Genuchten (1980) e, a partir deste modelo, foi determinada a declividade no ponto de inflexão da curva de retenção, obtendo-se o índice S (Dexter 2004).

\section{RESULTADOS E DISCUSSÃO}

Na Tabela 1, é apresentada a biomassa seca e o conteúdo de nitrogênio das diversas plantas de cobertura. O sorgo destacou-se como a cobertura de solo com o maior acúmulo de biomassa. Apesar do maior rendimento de matéria seca do sorgo, não foram observadas diferenças significativas entre as coberturas, exceto para o guandu, quanto ao teor de matéria orgânica do solo na camada $0,00-0,10 \mathrm{~m}$ (Figura 1). As plantas espontâneas, que cresceram no tratamento pousio, foram as que acumularam menor quantidade de biomassa, quando comparadas 
Tabela 1. Biomassa seca e conteúdo de nitrogênio (N) das plantas de cobertura do solo cultivadas em Latossolo Vermelho distrófico ( Santo Antônio de Goiás, GO, 2004).

\begin{tabular}{ccc}
\hline $\begin{array}{c}\text { Planta de } \\
\text { cobertura }\end{array}$ & $\begin{array}{c}\text { Biomassa seca } \\
\left(\mathrm{kg} \mathrm{ha}^{-1}\right)\end{array}$ & $\begin{array}{c}\text { Conteúdo de N } \\
\left(\mathrm{kg} \mathrm{ha}^{-1}\right)\end{array}$ \\
\hline Pousio & $1.942,0 \mathrm{c}^{1}$ & $39,7 \mathrm{~b}$ \\
Crotalária & $4.430,7 \mathrm{~b}$ & $123,0 \mathrm{a}$ \\
Guandu & $3.528,5 \mathrm{bc}$ & $99,7 \mathrm{ab}$ \\
Mucuna & $2.993,0 \mathrm{bc}$ & $84,0 \mathrm{ab}$ \\
Sorgo & $13.250,0 \mathrm{a}$ & $143,7 \mathrm{a}$ \\
\hline
\end{tabular}

${ }^{1}$ Valores seguidos da mesma letra não diferem entre si, pelo teste Tukey, a $5 \%$ de probabilidade.

às demais plantas de cobertura, possivelmente devido à heterogeneidade do banco de semente na área e ao preparo de solo.

Os valores da biomassa seca da crotalária e do guandu ficaram abaixo dos valores encontrados por Amabile et al. (2000), que observaram produções de $17,2 \mathrm{t} \mathrm{ha}^{-1}$, para crotalária, e 12,6 $\mathrm{t} \mathrm{ha}^{-1}$, para guan$\mathrm{du}$. Isto indica que, provavelmente, o rendimento da crotalária $\left(4,4 \mathrm{t} \mathrm{ha}^{-1}\right)$ e do guandu $\left(3,5 \mathrm{t} \mathrm{ha}^{-1}\right)$, semeados no outono (Tabela 1), tenha sido afetado pelas condições do ambiente e pelo fotoperíodo. $\mathrm{O}$ atraso na semeadura reduz as biomassas verde e seca produzidas pelo guandu e pela crotalária. Entretanto, deve ser observado que o fornecimento de biomassa é fundamental para a sustentabilidade dos sistemas agrícolas, em relação ao rendimento das culturas,

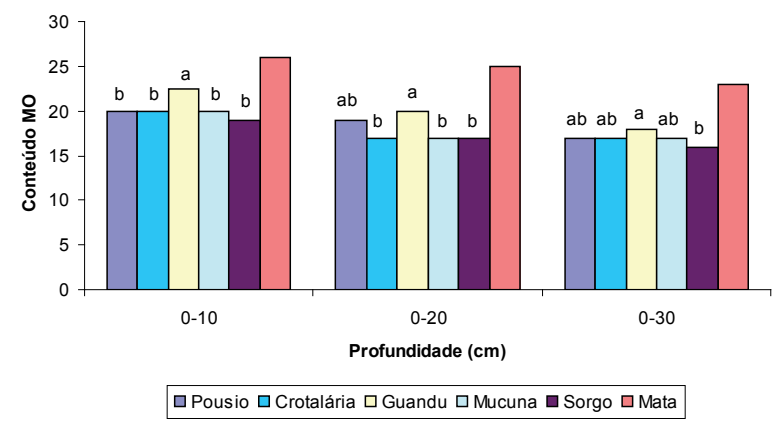

Figura 1. Conteúdos médios de matéria orgânica (MO), em diferentes profundidades de um Latossolo Vermelho distrófico, cultivado com diferentes plantas de cobertura do solo e sob mata (Santo Antônio de Goiás, GO, 2005).

e, também, em relação à melhoria das propriedades físicas, químicas e biológicas do solo (Amabile et al. 2000).

Os valores dos atributos físicos e do teor de matéria orgânica podem ser observados na Tabela 2 e Figura 1, respectivamente. Com relação à porosidade total, microporosidade e densidade do solo, não foram observadas diferenças significativas entre as profundidades, para as diferentes plantas de cobertura do solo, o que indica que a incorporação da biomassa das plantas de cobertura pela aração não foi suficiente para alterar estes parâmetros do solo em profundidade. Entretanto, o valor de porosidade total para o solo, sob sorgo, alcançou maior valor, em relação às

Tabela 2. Porosidade total (PT), microporosidade (MI), macroporosidade (MA), densidade do solo (Ds) e índice S de um Latossolo Vermelho distrófico, em diferentes profundidades, sob diferentes plantas de cobertura do solo e cultivado com arroz (Oryza sativa L.) de terras altas, cv. Aimoré (Santo Antônio de Goiás, GO, 2004).

\begin{tabular}{|c|c|c|c|c|c|c|}
\hline \multirow{2}{*}{ Tratamentos } & \multirow{2}{*}{$\begin{array}{l}\text { Profundidade } \\
\text { (cm) }\end{array}$} & $\mathrm{PT}$ & $\mathrm{MI}$ & MA & Ds & $\mathrm{S}$ \\
\hline & & $\mathrm{m}^{3} \mathrm{~m}^{-3}$ & $\mathrm{~m}^{3} \mathrm{~m}^{-3}$ & $\mathrm{~m}^{3} \mathrm{~m}^{-3}$ & $\mathrm{Mg} \mathrm{m}^{-3}$ & \\
\hline \multirow{3}{*}{ Pousio } & $0-10$ & $46,11 \mathrm{a}^{1}$ & $35,80 \mathrm{a}$ & $10,12 b$ & $1,44 \mathrm{a}$ & $0,023 \mathrm{a}$ \\
\hline & $10-20$ & $44,96 \mathrm{a}$ & $40,13 \mathrm{a}$ & $4,82 \mathrm{a}$ & $1,47 \mathrm{a}$ & $0,020 \mathrm{a}$ \\
\hline & $20-30$ & $45,16 \mathrm{a}$ & $39,65 \mathrm{a}$ & $5,51 \mathrm{a}$ & $1,47 \mathrm{a}$ & $0,020 \mathrm{a}$ \\
\hline \multirow{3}{*}{ Crotalária } & $0-10$ & $46,55 a$ & $40,54 \mathrm{a}$ & $6,01 \mathrm{a}$ & $1,43 \mathrm{a}$ & $0,022 \mathrm{a}$ \\
\hline & $10-20$ & $44,45 \mathrm{a}$ & $39,53 \mathrm{a}$ & $4,92 \mathrm{a}$ & $1,48 \mathrm{a}$ & $0,018 \mathrm{a}$ \\
\hline & $20-30$ & 44,89 a & $39,26 \mathrm{a}$ & $5,63 \mathrm{a}$ & $1,47 \mathrm{a}$ & $0,018 \mathrm{a}$ \\
\hline \multirow{3}{*}{ Guandu } & $0-10$ & $47,30 \mathrm{a}$ & $40,59 a$ & $6,70 a$ & $1,41 \mathrm{a}$ & $0,023 \mathrm{a}$ \\
\hline & $10-20$ & $46,17 \mathrm{a}$ & $40,51 \mathrm{a}$ & $5,66 \mathrm{a}$ & $1,45 \mathrm{a}$ & $0,021 \mathrm{a}$ \\
\hline & $20-30$ & $45,41 \mathrm{a}$ & $40,07 \mathrm{a}$ & $5,34 \mathrm{a}$ & $1,46 \mathrm{a}$ & $0,022 \mathrm{a}$ \\
\hline \multirow{3}{*}{ Mucuna } & $0-10$ & $48,15 \mathrm{a}$ & $34,80 \mathrm{a}$ & $13,34 \mathrm{~b}$ & $1,41 \mathrm{a}$ & $0,028 \mathrm{a}$ \\
\hline & $10-20$ & $47,17 \mathrm{a}$ & $38,27 \mathrm{a}$ & $12,80 \mathrm{a}$ & $1,34 \mathrm{a}$ & $0,022 \mathrm{ab}$ \\
\hline & $20-30$ & $46,19 \mathrm{a}$ & $36,24 \mathrm{a}$ & $9,94 \mathrm{a}$ & $1,44 \mathrm{a}$ & $0,018 \mathrm{~b}$ \\
\hline \multirow{3}{*}{ Sorgo } & $0-10$ & $50,81 \mathrm{a}$ & $38,89 \mathrm{a}$ & $11,91 \mathrm{~b}$ & $1,31 \mathrm{a}$ & $0,026 \mathrm{a}$ \\
\hline & $10-20$ & $44,76 \mathrm{a}$ & $39,41 \mathrm{a}$ & $5,35 \mathrm{a}$ & $1,48 \mathrm{a}$ & $0,020 \mathrm{a}$ \\
\hline & $20-30$ & $44,36 \mathrm{a}$ & $37,10 \mathrm{a}$ & $7,26 \mathrm{a}$ & $1,49 \mathrm{a}$ & $0,019 \mathrm{a}$ \\
\hline \multirow{3}{*}{ Mata } & $0-10$ & 66,70 & 33,46 & 33,28 & 0,89 & 0,099 \\
\hline & $10-20$ & 61,03 & 36,92 & 24,61 & 1,04 & 0,088 \\
\hline & $20-30$ & 49,09 & 37,09 & 12,00 & 1,36 & 0,031 \\
\hline
\end{tabular}

${ }^{1}$ Médias seguidas da mesma letra, na coluna, não diferem entre si, a $5 \%$ de probabilidade, pelo teste Tukey. 
outras profundidades. Provavelmente, isto pode ter ocorrido devido à alta produção de biomassa por esta cultura, que se concentrou nos primeiros centímetros de profundidade do solo, durante a incorporação no perfil, embora o teor de matéria orgânica nessa profundidade não fosse o maior do perfil (Figura 1). Este comportamento pode ser explicado pelas diferentes datas de amostragem para os parâmetros físicos, que foram feitas por ocasião do cultivo do arroz, em relação à matéria orgânica, determinada posteriormente à pré-incorporação das plantas de cobertura.

De maneira geral, observa-se, também, que a porosidade total, em quase todos os tratamentos, diminui com a profundidade, similarmente ao conteúdo de matéria orgânica, que também diminui com a profundidade. Para a densidade do solo, no tratamento sorgo, o menor valor de densidade aconteceu na camada superior amostrada. Esta diminuição pode ser creditada ao maior conteúdo de matéria orgânica alcançado neste tratamento e profundidade (Figura 1), em relação às demais plantas de cobertura.

Em relação à macroporosidade, observam-se, para pousio, mucuna e sorgo, na camada superficial, valores maiores que $0,10 \mathrm{~m}^{3} \mathrm{~m}^{-3}$. Segundo Kiehl (1979) e Dexter (1988), o crescimento de plantas tem sido associado a uma macroporosidade mínima de $0,10 \mathrm{~m}^{3} \mathrm{~m}^{-3}$, abaixo da qual a difusão de oxigênio torna-se limitante ao desenvolvimento das raízes. Assim, tais solos garantiriam suficiente aeração, permeabilidade e capacidade de retenção de água. Para a crotalária e guandu, na camada superficial, e para todas as coberturas, nas camadas subsuperficiais, exceto mucuna, os valores de macroporosidade ficaram abaixo do limite de $10 \mathrm{~m}^{3} \mathrm{~m}^{-3}$, caracterizando alguma compactação do solo.

Devido à não antropização, no solo sob mata nativa, observam-se os menores valores para a densidade do solo e microporosidade e maiores para porosidade total e macroporosidade, tanto para a camada superficial quanto para as camadas inferiores, em relação ao latossolo cultivado com as plantas de cobertura (Tabela 2). Silva et al. (2008) e Andrade et al. (2009) observaram resultados semelhantes, comparando solos de mata nativa e solos com diferentes tempos de adoção dos sistemas de preparo do solo. Para a matéria orgânica, os valores observados foram maiores que os das plantas de cobertura e diminuíram com a profundidade.

Para o índice $\mathrm{S}$, observa-se, para todos os tratamentos, somente na camada $0-10 \mathrm{~cm}$, valores acima de 0,020, o que indica que a biomassa das plantas de cobertura foi efetiva na melhoria da qualidade do solo somente em sua parte superficial. Os maiores valores ocorreram para solos cultivados com mucuna e sorgo. Mesmo os valores abaixo, mas próximos de 0,030 , na camada $0,00-0,10 \mathrm{~m}$, podem ser considerados satisfatórios, para solos com o perfil revolvido, uma vez que somente valores de $\mathrm{S}<0,020$ estão claramente associados a condições físicas de solos muito pobres.

As coberturas diferiram, significativamente, em profundidade somente para a mucuna, devido ao maior valor $(0,028)$ alcançado pelo índice $S$, na camada $0,00-0,10 \mathrm{~m}$. Nesta profundidade, embora o valor tenha ficado próximo a 0,030 , não houve correspondência em qualidade física para a densidade do solo, havendo, entretanto, correspondência para a macroporosidade, que alcançou o maior valor entre as plantas de cobertura e profundidades.

No solo sob mata, em todas as profundidades amostradas, o índice $\mathrm{S}$ foi maior que sob as diferentes coberturas, indicando maior qualidade física, concordando com Silva et al. (2008) e Andrade et al. (2009). Considerando-se o limite de $\mathrm{S}<0,020$, para solos degradados fisicamente, e $\mathrm{S} \geq 0,035$, para solo com boa qualidade física, de acordo com Dexter (2004), verifica-se que, na camada superficial do solo de todas as plantas de cobertura, este índice situou-se entre estes dois limites e, nas camadas abaixo, na grande maioria das situações, ficou próximo a 0,020 , sinalizando que o uso do solo no plantio convencional, independentemente da planta de cobertura, degrada sua qualidade física.

Na Tabela 3, estão expressos os valores da porcentagem de agregados e do DMP, para solo no sistema convencional. Observam-se diferenças significativas, para todas as plantas de cobertura, somente para agregados maiores que $2 \mathrm{~mm}$ e DMP. Os menores valores destas variáveis aconteceram na camada superficial 0,00-0,10 $\mathrm{m}$ de profundidade. Os valores de agregados $>2 \mathrm{~mm}$ e DMP podem ser considerados baixos no perfil, em comparação a valores obtidos para o sistema plantio direto, conforme destacam diversos autores (Alvarenga et al. 1986, Correa 2002, Wendling et al. 2002, Silva et al. 2008). Observa-se, também, que os maiores valores das variáveis aconteceram na camada $0,10-0,20 \mathrm{~m}$, para todas as plantas de cobertura, independentemente da quantidade de biomassa incorporada pela espécie. Embora o conteúdo de matéria orgânica não tenha sido o maior do 
Tabela 3. Porcentagem de agregados e diâmetro médio das partículas de um Latossolo Vermelho distrófico, em três profundidades, sob diferentes plantas de cobertura do solo e cultivado com arroz (Oryza sativa L.) de terras altas, cv. Aimoré (Santo Antônio de Goiás, GO, 2004).

\begin{tabular}{ccrrrrrrr}
\hline \multirow{2}{*}{ Tratamentos } & $\begin{array}{c}\text { Profundidade } \\
(\mathrm{cm})\end{array}$ & 2,0 & 1,0 & 0,5 & 0,25 & 0,125 & $<0,125$ & $\begin{array}{c}\text { DMP } \\
(\mathrm{mm})\end{array}$ \\
\cline { 2 - 7 } Pousio & $0-10$ & $25,29 \mathrm{~b}$ & $11,98 \mathrm{a}$ & $19,55 \mathrm{a}$ & $15,99 \mathrm{a}$ & $14,31 \mathrm{a}$ & $10,91 \mathrm{a}$ & $1,74 \mathrm{~b}$ \\
& $10-20$ & $36,67 \mathrm{a}$ & $14,83 \mathrm{a}$ & $18,73 \mathrm{a}$ & $14,20 \mathrm{a}$ & $8,98 \mathrm{a}$ & $6,60 \mathrm{a}$ & $2,26 \mathrm{a}$ \\
& $20-30$ & $28,56 \mathrm{a}$ & $14,52 \mathrm{a}$ & $21,29 \mathrm{a}$ & $16,16 \mathrm{a}$ & $10,07 \mathrm{a}$ & $9,40 \mathrm{a}$ & $1,88 \mathrm{a}$ \\
\hline \multirow{3}{*}{ Crotalária } & $0-10$ & $27,94 \mathrm{~b}$ & $10,59 \mathrm{a}$ & $18,62 \mathrm{a}$ & $16,72 \mathrm{a}$ & $11,29 \mathrm{a}$ & $14,84 \mathrm{a}$ & $1,78 \mathrm{~b}$ \\
& $10-20$ & $33,91 \mathrm{a}$ & $13,18 \mathrm{a}$ & $20,37 \mathrm{a}$ & $15,40 \mathrm{a}$ & $9,65 \mathrm{a}$ & $7,49 \mathrm{a}$ & $2,12 \mathrm{a}$ \\
& $20-30$ & $32,53 \mathrm{a}$ & $12,81 \mathrm{a}$ & $20,48 \mathrm{a}$ & $15,54 \mathrm{a}$ & $10,13 \mathrm{a}$ & $8,51 \mathrm{a}$ & $2,05 \mathrm{a}$ \\
\hline \multirow{3}{*}{ Guandu } & $0-10$ & $21,32 \mathrm{~b}$ & $12,45 \mathrm{a}$ & $21,87 \mathrm{a}$ & $18,28 \mathrm{a}$ & $14,67 \mathrm{a}$ & $22,39 \mathrm{a}$ & $1,51 \mathrm{~b}$ \\
& $10-20$ & $32,42 \mathrm{a}$ & $13,26 \mathrm{a}$ & $20,30 \mathrm{a}$ & $14,98 \mathrm{a}$ & $11,61 \mathrm{a}$ & $17,55 \mathrm{a}$ & $2,05 \mathrm{a}$ \\
& $20-30$ & $30,90 \mathrm{a}$ & $13,65 \mathrm{a}$ & $22,52 \mathrm{a}$ & $15,62 \mathrm{a}$ & $10,35 \mathrm{a}$ & $6,97 \mathrm{a}$ & $1,99 \mathrm{a}$ \\
\hline \multirow{3}{*}{ Mucuna } & $0-10$ & $33,28 \mathrm{~b}$ & $11,02 \mathrm{a}$ & $17,69 \mathrm{a}$ & $16,50 \mathrm{a}$ & $11,11 \mathrm{a}$ & $20,77 \mathrm{a}$ & $2,05 \mathrm{~b}$ \\
& $10-20$ & $38,30 \mathrm{a}$ & $12,85 \mathrm{a}$ & $19,21 \mathrm{a}$ & $14,00 \mathrm{a}$ & $9,27 \mathrm{a}$ & $6,37 \mathrm{a}$ & $2,32 \mathrm{a}$ \\
& $20-30$ & $33,86 \mathrm{a}$ & $13,22 \mathrm{a}$ & $21,96 \mathrm{a}$ & $16,64 \mathrm{a}$ & $9,84 \mathrm{a}$ & $15,35 \mathrm{a}$ & $2,14 \mathrm{a}$ \\
\hline \multirow{3}{*}{ Sorgo } & $0-10$ & $41,80 \mathrm{~b}$ & $9,68 \mathrm{a}$ & $18,46 \mathrm{a}$ & $12,91 \mathrm{a}$ & $9,69 \mathrm{a}$ & $7,46 \mathrm{a}$ & $2,44 \mathrm{~b}$ \\
& $10-20$ & $44,79 \mathrm{a}$ & $12,45 \mathrm{a}$ & $15,95 \mathrm{a}$ & $12,39 \mathrm{a}$ & $8,56 \mathrm{a}$ & $5,85 \mathrm{a}$ & $2,60 \mathrm{a}$ \\
& $20-30$ & $37,42 \mathrm{a}$ & $12,18 \mathrm{a}$ & $18,50 \mathrm{a}$ & $15,27 \mathrm{a}$ & $9,49 \mathrm{a}$ & $7,15 \mathrm{a}$ & $2,18 \mathrm{a}$ \\
\hline
\end{tabular}

${ }^{1}$ Médias seguidas da mesma letra, na coluna, não diferem entre si, a $5 \%$ de probabilidade, pelo teste Tukey.

perfil, nesta profundidade, para as diferentes plantas de cobertura, é possível que a matéria orgânica tenha sido protegida pela profundidade, influenciando na agregação do solo.

Além disso, deve-se levar em conta a distribuição da biomassa das plantas de cobertura, ao longo do perfil, pela ação de incorporação proporcionada pelo arado de aiveca. Assim, ao contrário do plantio direto, onde os restos culturais são mantidos na superfície do solo, a biomassa de plantas de cobertura, no SPC, é "diluída" em um volume grande de solo, com menor efeito na agregação do perfil. Para Tisdall \& Oades (1982), em solos cultivados, os agregados são expostos, frequentemente, à degradação física, quer pelo rápido umedecimento e pelo impacto da gota da chuva, quer pelo cisalhamento por implementos agrícolas. Uma vez que os agregados $>2 \mathrm{~mm}$ de diâmetro e outras partículas de solo sejam mantidos juntos, principalmente pela rede fina de raízes e hifas, é de se esperar que o seu percentual em solos preparados seja influenciado pelas práticas agrícolas.

Assim, as leguminosas são muito utilizadas como plantas de cobertura do solo porque, além do fornecimento de nitrogênio para o solo, contribuem para a distribuição dos agregados maiores que dois milímetros (Perin et al. 2002). Porém, as gramíneas também podem contribuir para uma melhor estabilidade dos agregados, conforme observado na Tabela 3, na qual o sorgo apresentou uma tendência de superioridade. Segundo Silva \& Mielniczuk (1997), os efeitos benéficos das gramíneas perenes na formação e estabilização desses agregados devem-se à alta densidade de raízes, que promovem a aproximação das partículas, pela constante absorção de água do perfil do solo; às periódicas renovações do sistema radicular; e à uniforme distribuição dos exsudatos no solo, que estimulam a atividade microbiana, cujos subprodutos atuam na formação e estabilização dos agregados. Tisdall \& Oades (1979) sugerem que o aumento da estabilidade de agregados, devido à ação de gramíneas, se deve à liberação de polissacarídeos por hifas de micorrizas associadas. As gramíneas também apresentam uma razão $\mathrm{C}: \mathrm{N}$ mais elevada, $\mathrm{o}$ que implica em maior permanência dos seus resíduos no solo, favorecendo o estabelecimento de cobertura na superfície (Igue 1984).

Em relação à mata, a redução do DMP e de agregados $>2 \mathrm{~mm}$, no perfil de solo sob preparo convencional, é esperada pelo revolvimento do solo, causado pelos equipamentos. Para os agregados $>2 \mathrm{~mm}$, Mendes et al. (2003) constataram reduções de 40\% no preparo com arado de discos, em relação à área de vegetação nativa. 


\section{CONCLUSÕES}

1. A incorporação da biomassa de diferentes plantas de cobertura ao solo não alterou as relações de porosidade e densidade do solo.

2. A incorporação da biomassa de sorgo modificou, significativamente, na camada 0-10 cm, o DMP e a porcentagem de agregados maiores que $2 \mathrm{~mm}$, o que também ocorreu com a incorporação da biomassa do pousio, da crotalária e da mucuna.

3. Os valores alcançados pelo índice $\mathrm{S}$ indicaram, na camada superficial, qualidade física intermediária do solo, quando incorporadas plantas de cobertura.

\section{REFERÊNCIAS}

ALVARENGA, R. C. et al. Estabilidade de agregados de um Latossolo Roxo sob diferentes métodos de preparo do solo e de manejo da palhada do milho. Revista Brasileira de Ciência do Solo, Viçosa, v. 10, n. 1, p. 273-277, 1986.

AMABILE, R. F.; FANCELLI, A. L.; CARVALHO, A. M. Comportamento de espécies de adubos verdes em diferentes épocas de semeadura e espaçamentos na região dos Cerrados. Pesquisa Agropecuária Brasileira, Brasília, DF, v. 35, n. 1, p. 47-54, 2000.

ANDRADE, R. da S.; STONE, L. F.; SILVEIRA, P. M. da. Culturas de cobertura e qualidade física de um latossolo em plantio direto. Revista Brasileira de Engenharia Agrícola e Ambiental, Campina Grande, v. 13, n. 4, p. 411-418, 2009.

BEUTLER, J. F. et al. Perdas de solo e água num Latossolo Vermelho aluminoférrico submetido a diferentes sistemas de preparo e cultivo sob chuva natural. Revista Brasileira de Ciência do Solo, Viçosa, v. 27, n. 3, p. 509-517, 2003.

CARPENEDO, V.; MIELNICZUK, J. Estado de agregação e qualidade dos agregados de Latossolos Roxos, submetidos a diferentes sistemas de manejos. Revista Brasileira de Ciência do Solo, Viçosa, v. 14, n. 1, p. 99-105, 1990.

CORREA, J. C. Efeito de sistemas de cultivo na estabilidade de agregados de um Latossolo VermelhoAmarelo em Querência, MT. Pesquisa Agropecuária Brasileira, Brasília, DF, v. 37, n. 2, p. 203-209, 2002.

DEXTER, A. R. Advances in characterization of soil structure. Soil Tillage Research, Amsterdam, v. 11, n. 3-4, p. 199-238, jun. 1988.

DEXTER, A. R. Soil physical quality: part II. Friability, tillage, tilth and hard-setting. Geoderma, Amsterdam, v. 120, n. 3-4, p. 215-225, 2004.
EMPRESA BRASILEIRA DE PESQUISA AGROPECUÁRIA (Embrapa). Centro Nacional de Pesquisas de Solos. Manual de métodos de análises de solo. 2. ed. Rio de Janeiro: Embrapa, 1997.

FREITAS, P. L. de. Aspectos físicos e biológicos do solo. In: LANDERS, J. N. Fascículos sobre experiências em plantio direto nos Cerrados. Goiânia: APDC, 1994. p. 199-213.

GENUCHTEN, M. T. Van. A closed form equation for predicting the hydraulic conductivity of unsaturated soils. Soil Science Society of America Journal, Madison, v. 44, n. 5, p. 892-898, 1980.

IGUE, K. Dinâmica da matéria orgânica e seus efeitos nas propriedades do solo. In: FUNDAÇÃO CARGILL. Adubação verde no Brasil. Campinas: Fundação Cargill, 1984. p. 232-267.

KIEHL, E. J. Manual de edafologia. São Paulo: Agronômica Ceres, 1979.

MENDES, I. C. et al. Propriedades biológicas em agregados de um Latossolo Vermelho-Escuro sob plantio convencional e direto no Cerrado. Revista Brasileira de Ciência do Solo, Viçosa, v. 27, n. 3, p. 435-443, 2003.

PERIN, A. et al. Efeito da cobertura viva com leguminosas herbáceas perenes na agregação de um Argissolo. Revista Brasileira de Ciência do Solo, Viçosa, v. 26, n. 3, p. 713-720, 2002.

PERIN, A.; TEIXEIRA, M. G.; GUERRA, J. G. M. Desempenho de algumas leguminosas com potencial para utilização como cobertura viva permanente de solo. Agronomia, Seropédica, v. 34, n. 1/2, p. 38-43, 2000.

PORTUGAL, A. F. et al. Atributos químicos e físicos de um Cambissolo Háplico Tb distrófico sob diferentes usos na zona da mata mineira. Revista Brasileira de Ciência do Solo, Viçosa, v. 32, n. 1, p. 242-258, 2008.

TISDALL, J. M.; OADES, J. M. Organic matter and waterstable aggregates in soils. Journal of Soil Science, London, v. 33, n. 2, p. 141-163, 1982.

TISDALL, J. M.; OADES, J. M. Stabilization of soil aggregates by the root systems of ryegrass. Australian Journal of Soil Research, Victoria, v. 17, n. 3, p. 429-441, 1979.

SALTON J. C. et al. Agregação e estabilidade de agregados do solo em sistemas agropecuários em Mato Grosso do Sul. Revista Brasileira de Ciência do Solo, Viçosa, v. 32, n. 1, p. 11-21, 2008.

SILVA, F. de F. da et al. Propriedades físicas de um Latossolo Vermelho cultivado no sistema plantio direto. Irriga, Botucatu, v. 13, n. 2, p. 191-204, 2008. 
SILVA, I. de F.; MIELNICZUK, J. Ação do sistema radicular de plantas na formação e estabilização de agregados do solo. Revista Brasileira de Ciência do Solo, Viçosa, v. 21, n. 1, p. 113-117, 1997.

SPEDDING, C. R. W.; LARGE, R. V. A point-quadrat method for the description of pasture in terms of height and density. Journal of the British Grassland Society, Oxford, v. 12 , n. 4, p. 229-234, 1957.
WENDLING, A. et al. Produtividade de grãos e massa seca de milho sob plantio direto no periodo de 1998-2002. Santa Maria: UFSM, 2002. 